\title{
A Novel Sandwich ELISA for Tartrate-Resistant Acid Phosphatase $5 a$ and $5 b$ Protein Reveals that Both Isoforms are Secreted by Differentiating Osteoclasts and Correlate to the Type I Collagen Degradation Marker CTX-I In Vivo and In Vitro
}

\author{
Laia Mira-Pascual ${ }^{1}$. Christina Patlaka ${ }^{1}$ - Suchita Desai ${ }^{1}$ - Staffan Paulie ${ }^{2}$ 'Tuomas Näreoja ${ }^{1}$ Pernilla Lång ${ }^{1}$ (i) . \\ Göran Andersson ${ }^{1}$
}

Received: 17 May 2019 / Accepted: 21 September 2019 / Published online: 25 October 2019

(c) The Author(s) 2019

\begin{abstract}
Tartrate-resistant acid phosphatase type 5 (TRAP) exists as two isoforms, $5 \mathrm{a}$ and $5 \mathrm{~b}$. $5 \mathrm{~b}$ is a marker of osteoclast number and $5 \mathrm{a}$ of chronic inflammation; however, its association with bone resorption is unknown. In this study, a double-TRAP $5 \mathrm{a} / 5 \mathrm{~b}$ sandwich ELISA measuring $5 \mathrm{a}$ and $5 \mathrm{~b}$ protein in the same sample was developed. TRAP $5 \mathrm{a}$ and $5 \mathrm{~b}$ protein levels were evaluated as osteoclast differentiation/activity markers in serum and in culture, and their correlation to the resorption marker CTX-I was examined. Serum TRAP 5a and $5 \mathrm{~b}$ concentrations in healthy men were $4.4 \pm 0.6 \mathrm{ng} / \mathrm{ml}$ and $1.3 \pm 0.2 \mathrm{ng} /$ $\mathrm{ml}$, respectively, and they correlated moderately to each other suggesting that their secretion is coupled under healthy conditions. A correlation was also observed between serum TRAP $5 \mathrm{a}$ and $5 \mathrm{~b}$ with CTX-I, suggesting that both TRAP isoforms associate with osteoclast number. During osteoclast differentiation on plastic/bone, predominantly $5 \mathrm{~b}$ increased in media/ lysate from M-CSF/RANKL-stimulated CD14+ PBMCs. However, substantial levels of 5a were detected at later stages suggesting that both isoforms are secreted from differentiating OCs. More TRAP $5 \mathrm{~b}$ was released on bone indicating a connection to osteoclast resorptive activity, and a peak in TRAP 5b/5a-ratio coincided with rapid CTX-I release. At the end of the culture period of M-CSF+ RANKL-stimulated CD14+ PBMCs, there was a correlation between the secretion of TRAP $5 \mathrm{a}$ and $5 \mathrm{~b}$ proteins with CTX-I. The correlation of not only $5 \mathrm{~b}$ but also $5 \mathrm{a}$ with collagen degradation, both in serum and osteoclast cultures indicates that a considerable proportion of the TRAP 5a originates from osteoclasts and may reflect a hitherto undisclosed regulatory mechanism during bone resorption and bone remodeling.
\end{abstract}

Keywords ELISA $\cdot$ Osteoclast $\cdot$ Acp5 $\cdot$ Bone resorption $\cdot$ Biomarker

Laia Mira-Pascual and Christina Patlaka contributed equally to this work. Also, Tuomas Näreoja and Pernilla Lång contributed equally to this work.

Electronic supplementary material The online version of this article (https://doi.org/10.1007/s00223-019-00618-w) contains supplementary material, which is available to authorized users.

Tuomas Näreoja tuomas.nareoja@ki.se

Pernilla Lång pernilla.lang@ki.se

Laia Mira-Pascual

laia.mira.pascual@ki.se

Christina Patlaka

c.patlaka@gmail.com

Suchita Desai suchita.desai@ki.se
Staffan Paulie

staffan.paulie@mabtech.com

Göran Andersson goran.andersson@ki.se

1 Division of Pathology, Department of Laboratory Medicine, Karolinska Institutet, Alfred Nobels Allé, 8, 14152 Stockholm, Sweden

2 Mabtech AB, Box 1233, 13128 Nacka Strand, Sweden 


\section{Introduction}

Tartrate-resistant acid phosphatase type 5 (TRAP; ACP5, EC 3.1.3.2) has been linked to osteoclast (OC) biology for decades, both with respect to the physiological function [1] and as a biomarker for bone resorption correlating to OC number [2].

TRAP has two isoforms in human sera, 5a and 5b. TRAP is translated as a monomeric protein, referred to as TRAP 5a of $\sim 35 \mathrm{kDa}$ in which a peptide loop (aa 165-177 in P13686, UniProt) interacts with the active site to prevent phosphatase activity [3]. Proteolytic cleavage in the loop region [3] results in the dimeric TRAP $5 \mathrm{~b}(16+23 \mathrm{kDa})$ [3] with augmented phosphatase activity. TRAP 5a has been regarded as a pro-form, however, it does have growth factor activity [4]. TRAP $5 \mathrm{~b}$ has been implied to regulate OC migration by dephosphorylation of osteopontin (OPN) [5], and inactivation of the human TRAP gene (Acp5) leads to hyperphosphorylation of OPN [6].

OC differentiation is initiated by receptor activator of nuclear factor kappa-B ligand (RANKL) leading to upregulated NFATc1 expression [7], inducing terminal OC differentiation by upregulation of OC-specific genes including Acp5 [8]. OC polarization increases TRAP expression and secretion into the ruffled border and resorption lacuna [9]. Secreted TRAP 5a in the resorption lacuna is processed, e.g., by cathepsin $\mathrm{K}$ (ctsK), to TRAP $5 \mathrm{~b}$ [10] which is also present in the transcytotic pathway and secreted from the functional secretory domain (FSD) [9]. In transcytotic vesicles, TRAP 5b could originate from two sources; (1) endocytosis of TRAP 5b, ctsK and bone degradation products in the resorption lacuna [9] and (2) fusion of acidic intracellular vesicles containing TRAP with vesicles trafficking along the transcytotic axis [9].

Today, there are commercially available TRAP assays measuring total TRAP or TRAP isoforms separately. Their chemistry is based on immuno-immobilization activity assays (IIAA), capturing total TRAP, i.e. TRAP $5 \mathrm{a}+5 \mathrm{~b}$, or specifically TRAP 5a and then measuring enzyme activity at respective $\mathrm{pH}$ optima for the two isoforms [11-13], or sandwich ELISA measuring TRAP 5a or total TRAP concentration [14-18].

TRAP $5 b$ activity measured using IIAAs correlates to OC number in vitro $[2,19]$ and in vivo [19], markers of bone turnover [20], and bone mineral density (BMD) [21]. Further, TRAP 5b measured using IIAAs has shown to be related to bone-associated disorders, e.g. rheumatoid arthritis (RA) [22, 23], hyperparathyroidism [24], and bone metastasis [25]. On the other hand, TRAP 5a has been shown to correlate to rheumatoid factor antibodies in RA and to the severity of the disease [26], although this correlation was suggested to originate from activated macrophages and therefore reflects only the inflammatory load [27]. Recently, TRAP 5a has also been shown to correlate to adipose tissue hyperplasia and body mass index (BMI) [28].

A key aspect to fully understand the relevance of TRAP $5 \mathrm{a}$ and $5 \mathrm{~b}$ in OC biology is to be able to measure $5 \mathrm{a}$ and $5 \mathrm{~b}$ protein separately, from the same sample, as measurement of TRAP activity can be confounded by different variables, e.g. redox state, composition of the active site, and the presence of bound serum proteins, e.g. alpha 2 macroglobulin (a2M). However, to date, there are no commercially available assays measuring TRAP $5 b$ protein or both TRAP $5 a$ and $5 b$ protein at the same time from the same sample.

Thus, the aim of this study was to develop a double-sandwich ELISA able to quantitate TRAP $5 \mathrm{a}$ and $5 \mathrm{~b}$ protein from the same sample simultaneously. Using the assay, we studied the correlation of TRAP isoforms and resorption marker, type I collagen c-terminal telopeptide (CTX-I) in the sera of healthy men. With human monocytes cultured on plastic or bone in vitro, we studied the use of TRAP $5 a, 5 b$ and $5 \mathrm{a} / 5 \mathrm{~b}$ as potential markers for OCs differentiation and function.

\section{Materials and Methods}

For a description of the methods regarding recombinant human TRAP $5 \mathrm{a}$ and $5 \mathrm{~b}$ production, generation, and purification of monoclonal antibodies against human TRAP $5 \mathrm{a}$ and total TRAP $(5 \mathrm{a}+5 \mathrm{~b})$, bone chips and bone-coated coverslips, TRAP activity staining of OC cultures, monoclonal antibodies (mAbs) affinity of mAb46 and mAb25.44 in the sandwich ELISA, culture of human OC, measurement of CTX-I and immunocytochemical TRAP staining of OC cultures, please see Supplementary Materials and Methods.

\section{Human Serum Samples and hPBMCs}

Healthy human adult male serum samples (Novakemi AB, Handen, Sweden) were used as quality control samples. They were aliquoted and stored at $-20{ }^{\circ} \mathrm{C}$. Median age was 47.8 years (range $29-65$ years). Human peripheral blood monocytes (hPBMC) were isolated from buffy coats of donated blood of healthy men at Karolinska University Hospital Laboratory, Huddinge, Sweden. The surplus blood products were coded for research use. The study was performed in accordance of guidelines from Swedish Research Council and Karolinska Institutet. All donors involved in the study gave written informed consent in accordance with the Helsinki Declaration. 
Incubate samples containing mixture of TRAP $5 a$ and TRAP $5 \mathrm{~b} \mathrm{O} / \mathrm{N}$ at $4^{\circ} \mathrm{C}$

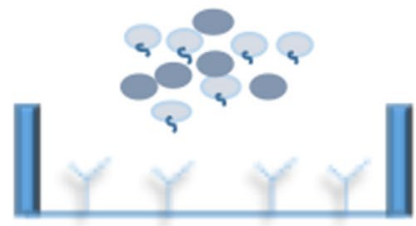

High capacity mAb 46 coated well

TRAP $5 a$

TRAP 5b

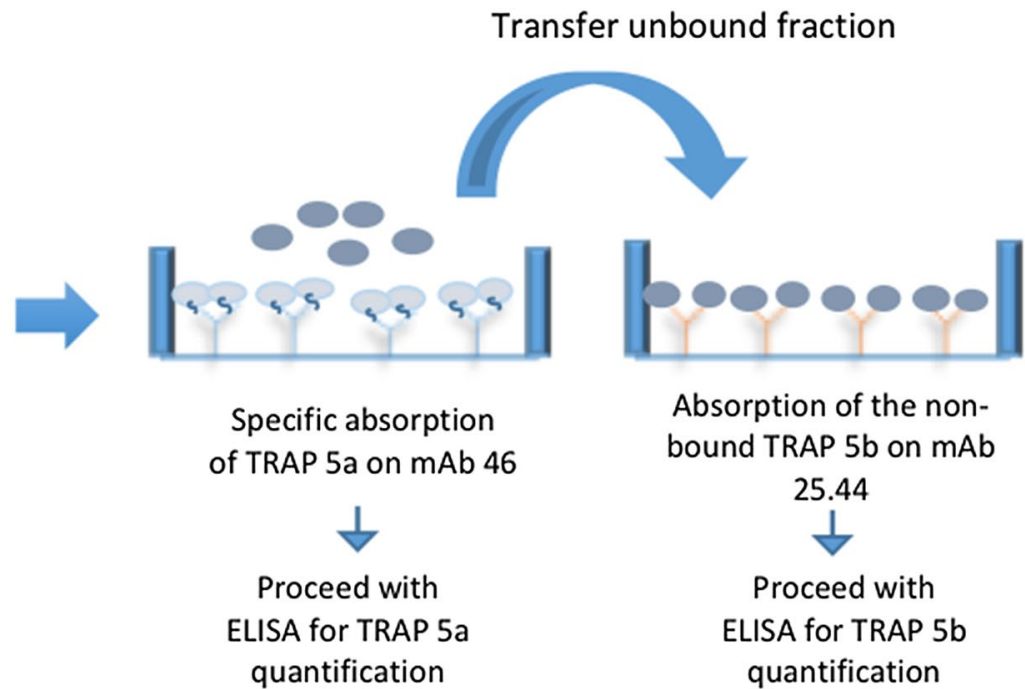

Fig. 1 Schematic outline of the double-TRAP 5a/5b sandwich ELISA for TRAP isoform separation and quantification

\section{Design of the Double-Sandwich ELISA Measuring TRAP 5a and 5b Protein from One and the Same Sample}

In order to separate TRAP 5a from TRAP 5b, the method was designed as follows (Fig. 1): In the first step, a sample was added to TRAP 5a-specific antibody (mAb 46)-coated wells. TRAP 5a was captured on mAb 46 antibodies and, after overnight incubation at $+4{ }^{\circ} \mathrm{C}$, the sample, depleted of TRAP 5a but having the original amount of TRAP 5b, was transferred to wells coated with mAb 25.44, recognizing both isoforms. Subsequently, the bound TRAP 5a in the first well was detected using biotinylated mAb 12.56 biotin/ streptavidin-conjugated HRP and the remaining TRAP $5 \mathrm{~b}$ in the second well was measured using biotinylated mAb 12.56 and biotin/streptavidin-conjugated HRP.

\section{Optimization of the Double-TRAP $5 \mathrm{a} / 5 \mathrm{~b}$ Sandwich ELISA Quantifying Human TRAP Isoforms $5 a$ and $5 b$ Protein Independently in One and the Same Sample}

General protocol for double-sandwich ELISA quantifying TRAP $5 \mathrm{a}$ and $5 \mathrm{~b}$ protein independently in one and the same sample: 96-well $1 / 2$ volumes ELISA plates (Costar, New York, NY) were coated with $5 \mu \mathrm{g} / \mathrm{ml}(100 \mu \mathrm{l} /$ well $) \mathrm{mAb} 46$ or $(50 \mu \mathrm{l} /$ well $) \mathrm{mAb} 25.44$ diluted in PBS (0.01 M pH 7.4) and left at $4{ }^{\circ} \mathrm{C}$ overnight. Next day, mAb 46 -coated plates were washed 3 times in TBST $(200 \mu \mathrm{l} /$ well; $25 \mathrm{mM}$ Tris 7.6, $150 \mathrm{mM} \mathrm{NaCl}, 0.1 \%$ Tween 20). After washing, pretreated standards and samples, for procedure see "Sample preparation: pre-treatment" ( $65 \mu \mathrm{l} /$ well $)$ were added to $\mathrm{mAb}$ 46-coated plate and incubated overnight at $4{ }^{\circ} \mathrm{C}$. Supernatant (samples and TRAP 5a standard curve) was then transferred
( $50 \mu \mathrm{l} /$ well) from mAb 46-coated plate to mAb 25.44-coated plate (Fig. 1). Also, fresh standard curve for TRAP 5a was added to the mAb 25.44-coated plates and incubated for $2 \mathrm{~h}$ at room temperature. Plates were washed 3 times in TBST (200 $\mu \mathrm{l} /$ well) and incubated with $0.25 \mu \mathrm{g} / \mathrm{ml}$ biotinylated detection $\mathrm{mAb} 12.56(50 \mu \mathrm{l} /$ well $)$ diluted in $0.1 \%$ bovine serum albumin (BSA) + TBST for $1 \mathrm{~h}$ at room temperature. Next, plates were washed 3 times in TBST ( $200 \mu 1 /$ well) and incubated with streptavidin-HRP (Mabtech) diluted $1: 1000$ in $0.1 \% \mathrm{BSA}+\mathrm{TBST}(50 \mu \mathrm{l} /$ well $)$ for $1 \mathrm{~h}$ at room temperature. Finally, plates were washed 3 times in TBST $(200 \mu 1 /$ well $)$ and developed using K-Blue ${ }^{\circledR}$ Substrate (TMB) (Neogen, Lansing, MI) $(50 \mu \mathrm{l} /$ well $)$ and the reaction was stopped with $1 \mathrm{M} \mathrm{H}_{2} \mathrm{SO}_{4}(50 \mu \mathrm{l} /$ well). Absorbance was read at $450 \mathrm{~nm}$ using BioTek's PowerWave HT microplate spectrophotometer (BioTek, Winooski, VT). Affinities of mAb 46 and $\mathrm{mAb} 25.44$ were compared in a sandwich ELISA. TRAP 5a and TRAP 5b standards were added to $\mathrm{mAb}$ 46- or $\mathrm{mAb} 25.44$-coated plates followed by incubation overnight. Next day, ELISA assay was performed as described above.

\section{Total TRAP Sandwich ELISA}

Total TRAP sandwich ELISA was performed as the previously described TRAP 5a ELISA [28] and as described above under section "General protocol for double sandwich ELISA quantifying TRAP $5 \mathrm{a}$ and $5 \mathrm{~b}$ protein independently in one and the same sample" with the exception that plates were coated with $5 \mu \mathrm{g} / \mathrm{ml} \mathrm{mAb} 25.44$ and no transfer is needed. 
Limit of blank (LoB), limit of detection (LoD), and limit of quantification (LoQ) were calculated as previously described [29].

Inter-assay variation was estimated by calculating CV \% of four separate runs. It was calculated using human serum samples with TRAP concentrations above or equal to LoD (see "Human Serum Samples") ( $n=18)$.

Intra-assay variation was determined using 16 technical replicates of 11 human serum samples of TRAP 5a and 5b concentrations at different points of the detection range (see "Human Serum Samples").

\section{Pre-treatment of Samples and Standard Curves}

For pre-treatment, serum samples $(30 \mu \mathrm{l})$ were diluted 1:1 with $1.5 \mathrm{M}$ glycine $\mathrm{pH} 2.5(30 \mu \mathrm{l})$ and incubated for $1 \mathrm{~h}$ at $37^{\circ} \mathrm{C}$. After incubation, samples were neutralized by addition of 1 volume $(30 \mu \mathrm{l}) 1 \mathrm{M}$ Tris- $\mathrm{HCl} \mathrm{pH}$ 8.5. Samples were further diluted by an additional 3 volumes $(90 \mu \mathrm{l})$ of Diluent ELISA (Mabtech) leading to final dilution of serum samples 1:6. Standard curves were directly diluted in $1.5 \mathrm{M}$ glycine $\mathrm{pH} 2.5$, followed by the addition of 1 volume $1 \mathrm{M}$ Tris- $\mathrm{HCl} \mathrm{pH}$ 8.5, and 3 volumes of Diluent ELISA giving a final dilution of 1:6.

\section{Correction of TRAP 5a Carry-over When Quantifying TRAP 5b}

First, the amount of TRAP 5a on mAb 46 plate was calculated from the TRAP 5a standard curve. Then the TRAP 5a standard curve was transferred to $\mathrm{mAb} 25.44$ plate and the values from samples were recorded to produce a carry-over standard curve to obtain the expected absorbance left over at different concentrations. The carry-over of TRAP 5a value was then subtracted from the TRAP $5 b$ sample values from $\mathrm{mAb} 25.44$ before the actual concentrations were interpolated from the TRAP $5 b$ standard curve.

\section{Statistical Calculations}

Standard curves for TRAP 5a and TRAP 5b were compared using curve fit with linear regression. Serum total TRAP and TRAP $5 b+5 a$ without and with correction were analyzed using Wilcoxon matched-pairs signed-rank test. Correlations between CTX-I, TRAP 5a, and TRAP 5b were made using Spearman correlation. Differences in TRAP 5a and $5 \mathrm{~b}$ protein levels in lysate and media were analyzed using Mann-Whitney $U$ test. $p$ values $<0.05$ were considered significant.

\section{Results}

\section{Optimization of the Double-TRAP $5 \mathrm{a} / 5 \mathrm{~b}$ Sandwich ELISA}

The sandwich ELISA (Fig. 1) using mAb 46 as capture antibody, raised against the loop region specific for TRAP 5a, detected in a dose-dependent manner specifically TRAP 5a, but not TRAP 5b ( $p=0.0003$; Fig. 2a), in line with previous studies [28]. mAb 25.44 capture antibody detected both TRAP 5a and 5b in a dose-dependent manner with the same affinity ( $p=0.9591$; Fig. 2 b). In cross screening of antibodies raised against recombinant TRAP 5a, detector antibody $\mathrm{mAb} 12.56$ was superior against both capture antibodies.

Examination of TRAP 5a and 5b carry-over showed that TRAP $5 \mathrm{~b}$ protein concentration was not affected by previous incubation on mAb 46 (Fig. 2c). However, a fraction of TRAP 5a was not immobilized on mAb 46 but was carried over to mAb 25.44 during sample transfer (Fig. 2c). This carry-over of TRAP $5 \mathrm{a}$ would lead to falsely high TRAP $5 \mathrm{~b}$ protein levels, since the mAb 25.44 does not discriminate between the isoforms. The error caused by carry-over TRAP 5 a could be compensated by transferring also the TRAP 5a standard curve to mAb 25.44 and subtracting the amount of TRAP 5a carry-over to the wells detecting TRAP 5b (Fig. 2d, f). In serum, correcting for TRAP 5a carry-over resulted in TRAP $5 \mathrm{a}+5 \mathrm{~b}$ protein concentrations that were equal to total TRAP protein concentration while the sum of TRAP $5 a+5 b$ protein concentrations without correction gave significantly higher TRAP concentrations than total TRAP measurement (Fig. 2e).

In serum, TRAP can be found in a complex formed with a2M, which may impair TRAP 5a and 5b detection, therefore the effect of pre-treatment of serum samples using acidification to promote dissociation of a2M-TRAP complexes was investigated. TRAP 5a concentrations measured in pre-treated serum were significantly higher $(p<0.0450)$ compared to non-treated samples (Fig. 3a). On the other hand, pre-treatment of serum had no effect on amount of TRAP $5 b$ or total TRAP detected on mAb 25.44 (Fig. 3b, c). This effect of pre-treatment on TRAP $5 \mathrm{a}$ on mAb 46 was not observed with the recombinant proteins or samples from in vitro human $\mathrm{OC}$ cultures (data not shown).

\section{TRAP $5 a$ and TRAP $5 b$ Correlate to Each Other as Well as to Resorption Marker CTX-I in the Sera of Healthy Men}

Both inter- and intra-assay variations for TRAP 5a and TRAP $5 b$ in the double-TRAP 5a/5b sandwich ELISA were within an acceptable range (below 20\%) (Table 1). The LoD 

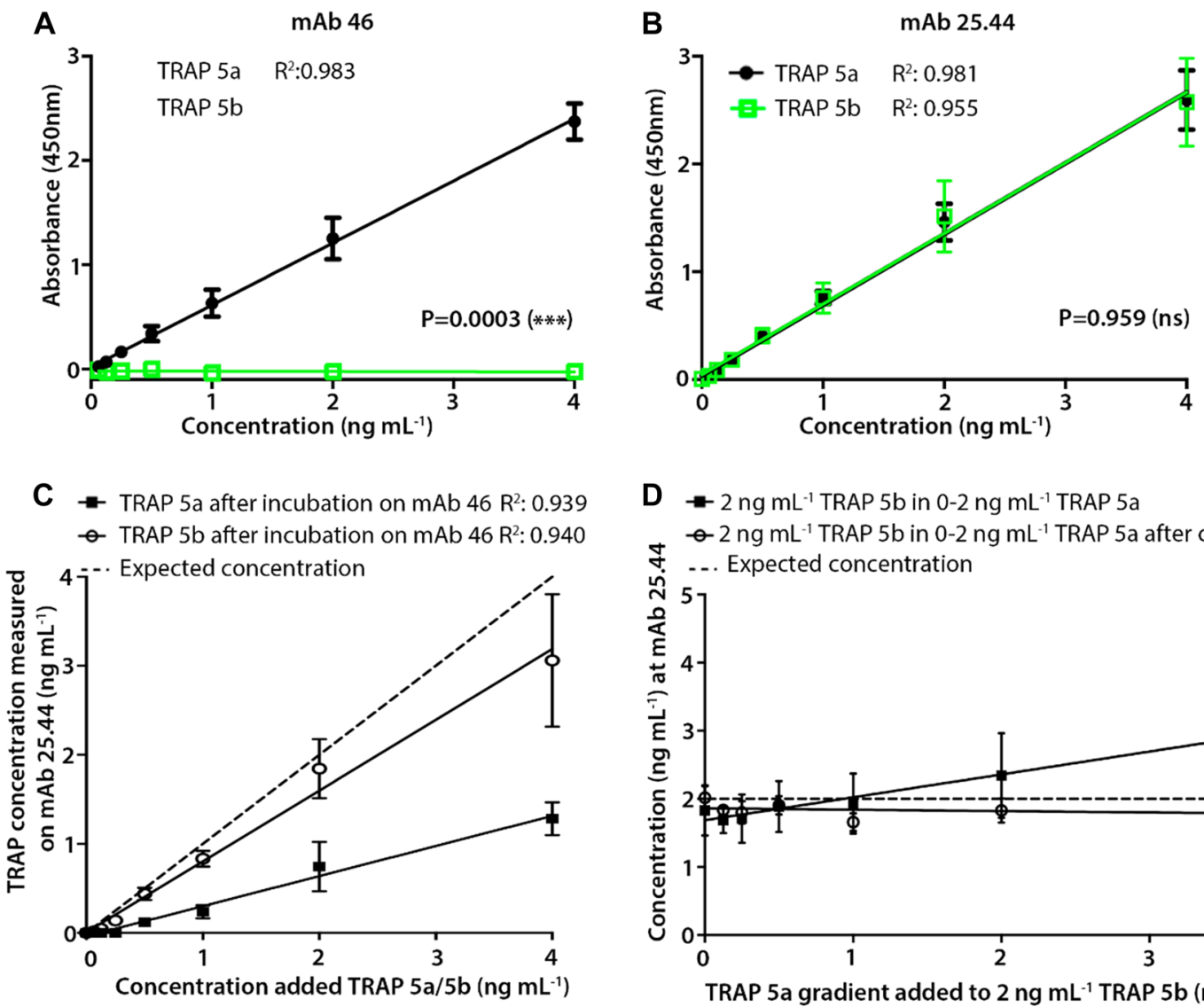
D $-2 n g ~ m L^{-1}$ TRAP $5 b$ in 0-2 $\mathrm{ng} \mathrm{mL}^{-1}$ TRAP $5 \mathrm{a}$

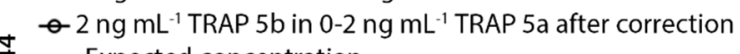
... Expected concentration

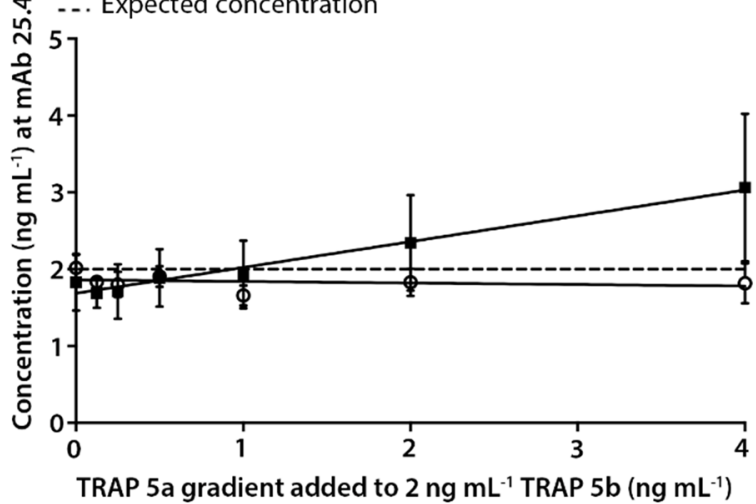

E

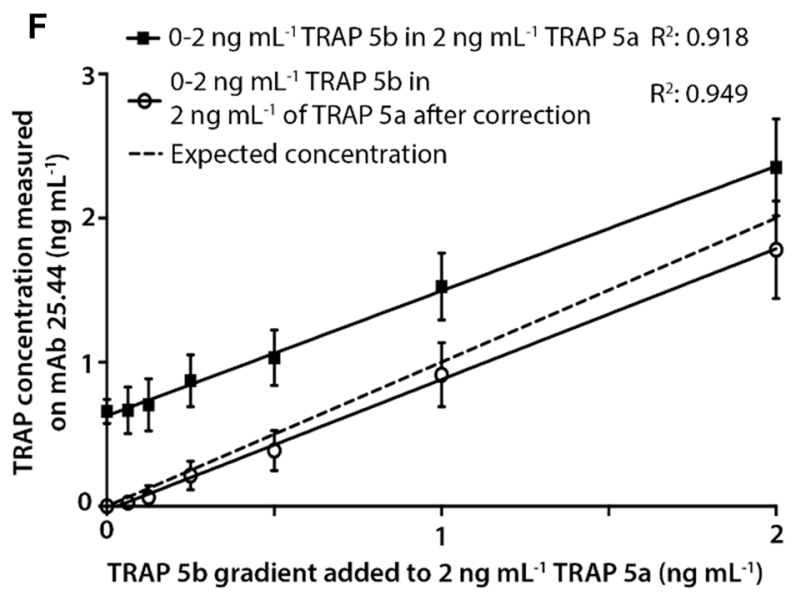

Fig. 2 Antibody specificity and TRAP 5a carry-over correction. a TRAP 5a 0-2 $\mathrm{ng} / \mathrm{ml}$ and TRAP $5 \mathrm{~b} 0-2 \mathrm{ng} / \mathrm{ml}$ were added in the sandwich ELISA using mAb 46 as capture antibody. The curves were fitted using linear regression $(n=3)$. b TRAP 5 a $0-2 \mathrm{ng} / \mathrm{ml}$, TRAP 5 b $0-2 \mathrm{ng} / \mathrm{ml}$ were added in the sandwich ELISA using mAb 25.44 as a capture antibody and fitted using linear regression $(n=3)$. c Measurement of $0-4 \mathrm{ng} / \mathrm{ml}$ TRAP $5 \mathrm{a}$ and TRAP $5 \mathrm{~b}$ on mAb 25.44 sandwich ELISA after overnight incubation on mAb $46(n=3)$. d Measurement of $2 \mathrm{ng} / \mathrm{ml}$ TRAP $5 \mathrm{~b}$ diluted in $0-2 \mathrm{ng} / \mathrm{ml}$ TRAP 5 a with or without correction for remaining TRAP 5 a carry-over $(n=3)$. e Concen-

tration of total TRAP (TRAP 5a + TRAP 5b) in serum measured by direct incubation on mAb 25.44 or as the sum of separate measurement of TRAP 5a and TRAP 5b on mAb 46 and mAb 25.44, respectively. Concentrations were calculated with or without background correction for TRAP $5 b$ measurement carry-over. TRAP 5a+TRAP $5 \mathrm{~b}$ were compared to total TRAP using Wilcoxon matched-pairs signed-rank test $(n=16)$. Values are given as mean absorbance \pm SD in $\mathbf{a}, \mathbf{b}$ and mean \pm SD in $\mathbf{c}-\mathbf{f}$. ${ }^{*} p \leq 0.05$. f Measurement of $0-2 \mathrm{ng} / \mathrm{ml}$ TRAP $5 b$ in $2 \mathrm{ng} / \mathrm{ml}$ TRAP $5 \mathrm{a}$ with or without correction for TRAP 5a carry-over $(n=3)$ 
Fig. 3 Serum acid pre-treatment increases detection of TRAP 5a but not TRAP 5b. a Absorbance of serum samples on $\mathrm{mAb}$ 46 sandwich ELISA with or without serum pre-treatment (mean $\pm \mathrm{SD}, n=6$ ), measuring TRAP 5a. b Absorbance of serum samples on $\mathrm{mAb}$ 25.44 sandwich ELISA with or without serum pre-treatment (mean $\pm \mathrm{SD}, n=6$ ) after transfer, measuring TRAP $5 b$. c The absorbance of serum samples on 25.44 sandwich ELISA with or without serum pretreatment (mean $\pm \mathrm{SD}, n=6$ ) without transfer, measuring total TRAP
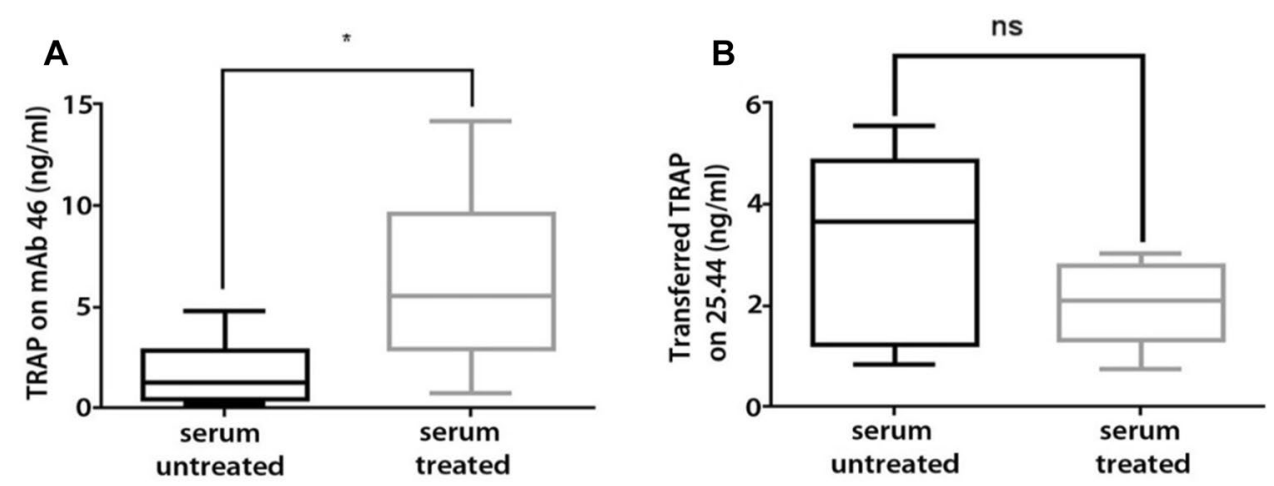

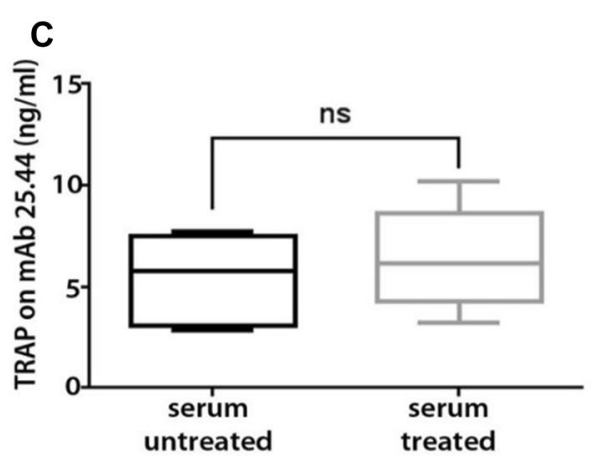

Table 1 TRAP 5a and TRAP 5b measurement in sera of healthy men and inter-, intra-assay CV \%, lower limit of blank, lower limit of detection, and lower limit of quantitation for TRAP $5 \mathrm{a}(\mathrm{mAb} 46)$ and TRAP $5 \mathrm{~b}$ (mAb 25.44)

\begin{tabular}{|c|c|c|c|c|}
\hline & TRAP 5a & TRAP $5 b$ & & \\
\hline Mean \pm SD $(n g / m l)(n=18)$ & $4.4 \pm 0.6$ & $1.4 \pm 0.2$ & & \\
\hline Lower $95 \%$ CI of mean $(\mathrm{ng} / \mathrm{ml})$ & 4.2 & 0.9 & & \\
\hline Upper $95 \%$ CI of mean $(\mathrm{ng} / \mathrm{ml})$ & 5.8 & 1.8 & & \\
\hline Ratio \pm SD (\%) & $75.3 \pm 6.9$ & $24.7 \pm 6.9$ & & \\
\hline Lower limit of blank (LoB) (ng/ml) & $0.23 \pm 0.01$ & $0.04 \pm 0.02$ & & \\
\hline Lower limit of detection $(\mathrm{LoD})(\mathrm{S} / \mathrm{N}=3)(\mathrm{ng} / \mathrm{ml})$ & 0.30 & 0.05 & & \\
\hline \multirow[t]{2}{*}{ Lower limit of quantitation (LoQ) (ng/ml) } & $0.35^{\mathrm{a}}$ & $0.09^{\mathrm{b}}$ & & \\
\hline & Low (ng/ml) & High (ng/ml) & Low (ng/ml) & High $(\mathrm{ng} / \mathrm{ml})$ \\
\hline Inter-assay mean $\mathrm{CV} \%(N=4)$ & $13.7(n=6)^{\mathrm{A}}$ & $9.4(n=12)^{\mathrm{B}}$ & $15.4(n=10)^{\mathrm{A}}$ & $17.7(n=8)^{\mathrm{B}}$ \\
\hline Intra-assay mean $\mathrm{CV} \%(N=16)$ & $16.7(n=5)^{\mathrm{C}}$ & $12.54(n=6)^{\mathrm{D}}$ & $16.1(n=6)^{\mathrm{C}}$ & $12.9(n=5)^{\mathrm{D}}$ \\
\hline
\end{tabular}

Technical parameters describing assay performance are presented as measured values in respect to the standard curve, while concentrations of the clinical samples are shown as the true serum concentration

For inter- and intra-assay "Low" is defined as a group of samples with a concentration below and "High" as a group of samples with a concentration above mean serum TRAP $5 \mathrm{a}$ or $5 \mathrm{~b}$

${ }^{\mathrm{a}}$ Calculated from a sample with measured concentration of $0.35 \mathrm{ng} / \mathrm{ml}$ and $\mathrm{CV} \% 12.9$, the final serum concentration of $0.35 * 6$ (dilution factor) $=2.1 \mathrm{ng} / \mathrm{ml}$

${ }^{\mathrm{b}}$ Calculated from a sample with measured concentration of $0.09 \mathrm{ng} / \mathrm{ml}$ and $\mathrm{CV} \%$ 8.2, the final serum concentration of $0.09 * 6$ (dilution factor) $=0.5 \mathrm{ng} / \mathrm{ml}$

${ }^{A}$ Concentration range TRAP $5 \mathrm{a}(2.1-3.1 \mathrm{ng} / \mathrm{ml})$ and $5 \mathrm{~b}(0.5-1.3 \mathrm{ng} / \mathrm{ml})$

${ }^{\mathrm{B}}$ Concentration range TRAP $5 \mathrm{a}(4.4-11.6 \mathrm{ng} / \mathrm{ml})$ and $5 \mathrm{~b}(1.4-2.5 \mathrm{ng} / \mathrm{ml})$

${ }^{\mathrm{C}}$ Concentration range TRAP $5 \mathrm{a}(0.9-4.4 \mathrm{ng} / \mathrm{ml})$ and $5 \mathrm{~b}(0.9-2.2 \mathrm{ng} / \mathrm{ml})$

${ }^{\mathrm{D}}$ Concentration range TRAP $5 \mathrm{a}(5.3-9.6 \mathrm{ng} / \mathrm{ml})$ and $5 \mathrm{~b}(2.2-3.6 \mathrm{ng} / \mathrm{ml})$ 


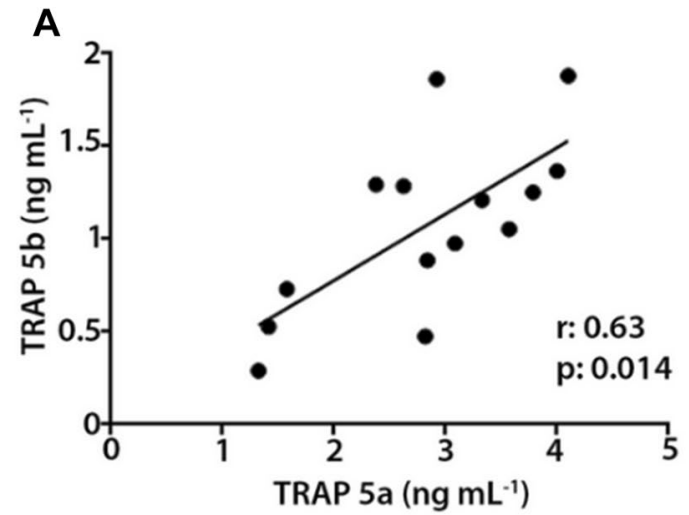

B

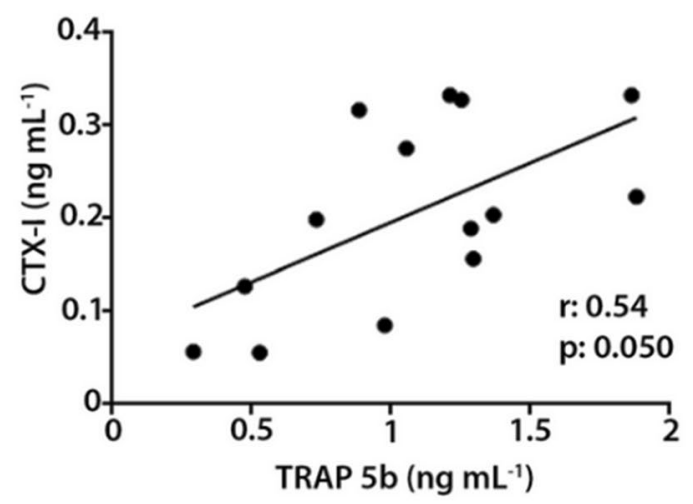

C

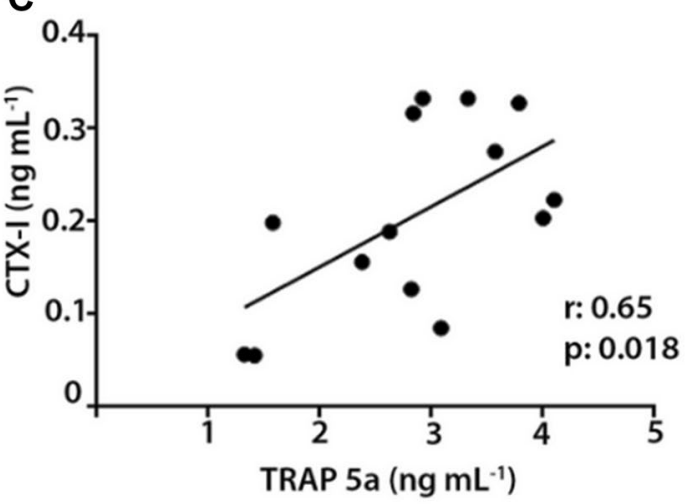

Fig. 4 Correlation between TRAP 5a and TRAP 5b in the sera of healthy men and the resorption marker CTX-I. a Correlation between TRAP $5 \mathrm{~b}$ and TRAP $5 \mathrm{a}(n=14)$. b Correlation between TRAP $5 \mathrm{~b}$ and CTX-I $(n=14)$. c Correlation between TRAP 5a and CTX-I $(n=14)$. Correlation analysis was done using Spearman's correlation

values were $0.3 \mathrm{ng} / \mathrm{ml}$ and $0.05 \mathrm{ng} / \mathrm{ml}$ for TRAP $5 \mathrm{a}$ and $5 \mathrm{~b}$, respectively. No degradation of TRAP $5 b$ recombinant protein or decrease in TRAP $5 b$ protein concentrations in serum samples was seen over time (Supplementary figure 1).

In healthy adult men, TRAP 5a concentration was $4.4 \pm 0.6 \mathrm{ng} / \mathrm{ml}$ and TRAP $5 \mathrm{~b}$ was $1.3 \pm 0.2 \mathrm{ng} / \mathrm{ml}$, respectively (Table 1). Thus, isoform 5 a constituted $75 \%$ of serum TRAP protein while isoform $5 \mathrm{~b}$ accounted for $25 \%$, i.e. a ratio of 3:1 (Table 1). In serum, TRAP $5 a$ and $5 b$ protein concentrations correlated moderately positively (for definition see [30]) to each other (Fig. 4a). Also, TRAP 5b protein levels correlated moderately positively with the collagen degradation marker CTX-I (Fig. 4b) which is in line with previous results [31]. Interestingly, TRAP 5a also showed a positive moderate correlation to CTX-I (Fig. 4c).

\section{Osteoclast Differentiation of CD14+ Peripheral Blood Monocytes (PBMCs) on Plastic and Bone}

To validate TRAP isoforms as biomarkers, we measured their production on active (bone) and inactive (plastic) substrates by human CD14+ PBMCs. The PBMCs were isolated from 6 healthy male donors and cultured on cell culture plastic in the presence of $30 \mathrm{ng} / \mathrm{ml}$ macrophage colony stimulating factor (M-CSF) and $2 \mathrm{ng} / \mathrm{ml}$ RANKL or $30 \mathrm{ng} / \mathrm{ml} \mathrm{M-CSF}$ alone as a control. In the presence of RANKL + M-CSF, multinucleated TRAP-positive osteoclast-like cells started to appear at day 4, whereas in cultures with M-CSF alone, aggregated cell clusters and a few TRAP-positive mononuclear cells but no multinucleated cells were observed at this time-point (Supplementary figure 3A). On day 6 with RANKL and M-CSF, there were abundant osteoclast-like multinuclear cells with strong TRAP signal and only a few TRAP-positive mononuclear cells. With M-CSF alone, there was an abundance of mononuclear TRAP-positive cells but no multinucleated cells.

On bone, the difference between RANKL + M-CSF and M-CSF alone on CD14+ PBMCs was even more pronounced, however, the time course of OC differentiation was somewhat delayed compared to differentiation on plastic (Supplementary figure 3B). At day 4, with both M-CSF alone and RANKL + M-CSF, only TRAP-positive mononuclear cells were attached to bone, whereas at day 8 and onwards, TRAP-positive multinucleated cells appeared only in M-CSF + RANKL-stimulated cultures. With M-CSF alone, there were only few TRAP-positive mononuclear cells. Furthermore, deep resorption pits were observed on bone slices on which RANKL-stimulated cells were cultured, confirming their identity as OCs (Supplementary figure 3C). These pits were stained TRAP-positive, especially the edges of the pit, indicating secretion of TRAP during resorption.

\section{Distribution of TRAP 5a and 5b Isoforms in Osteoclasts and Mononuclear Cells on Glass and Bone}

To confirm that the mAb 46 and mAb 25.44 indeed identify different targets and different timepoints of OC differentiation and function, we conducted immunocytochemical (ICC) staining of the TRAP isoforms. The distribution and localization of intracellular TRAP isoforms $5 \mathrm{a}$ and $5 \mathrm{~b}$ in 
A Actin

total TRAP

Merge of TRAP5a
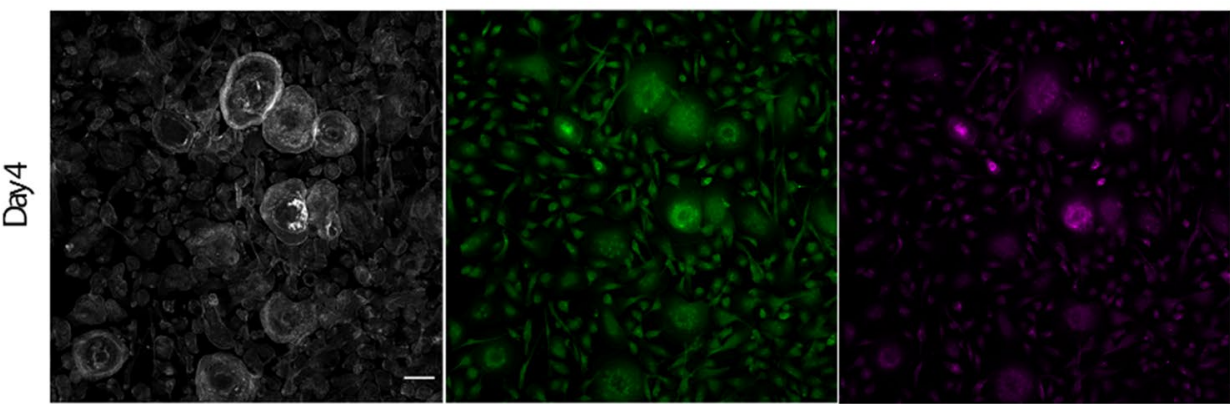

and totalTRAP
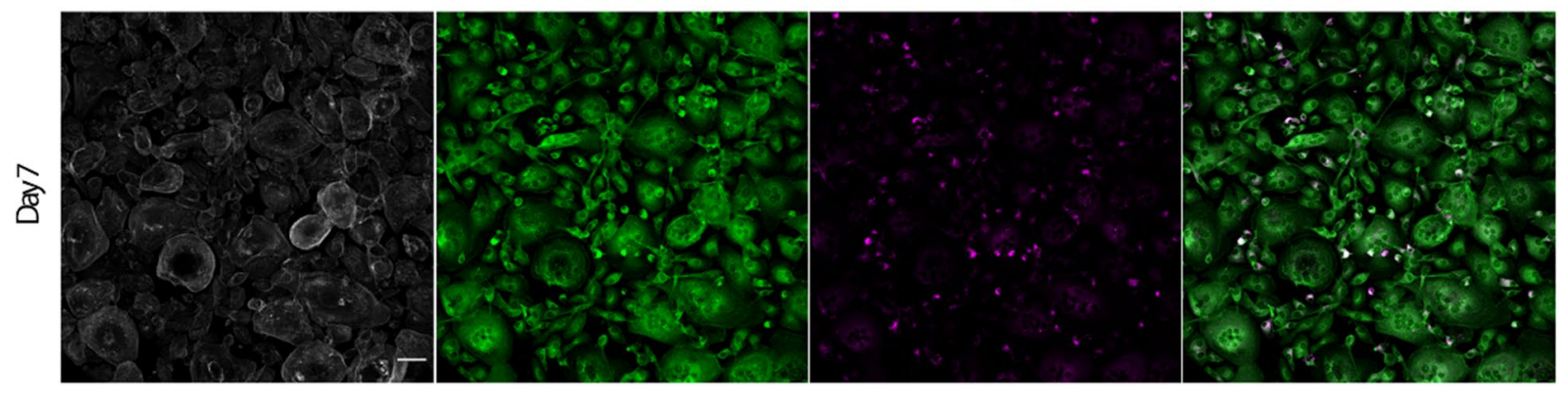

B
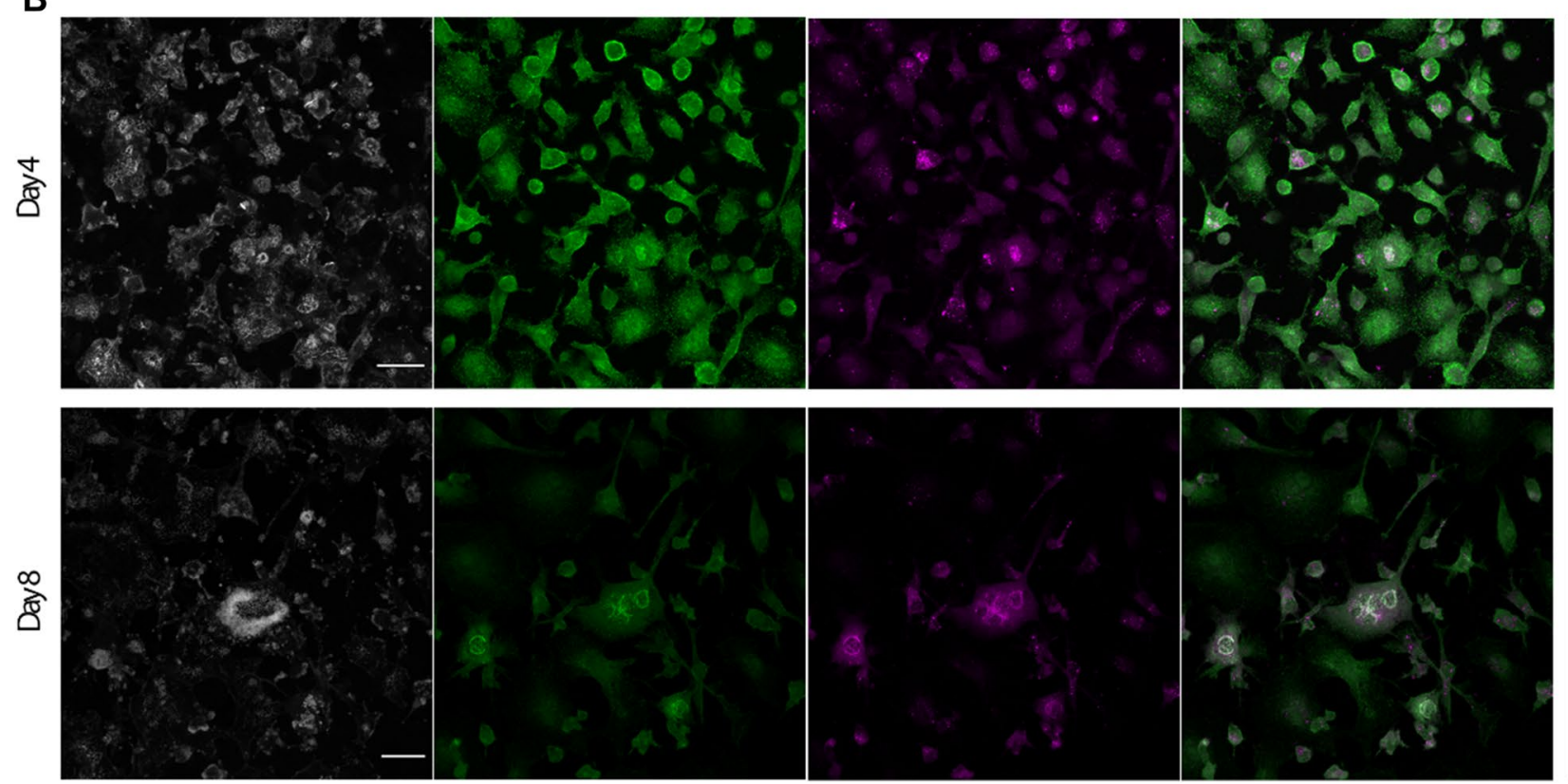

Fig. 5 Immunocytochemical staining of TRAP isoforms in M-CSFand RANKL-stimulated cultures of CD14+ PBMCs. a Staining for TRAP isoforms TRAP 5a (green), total TRAP (magenta), and actin (gray) of stimulated PBMCs with $30 \mathrm{ng} / \mathrm{ml} \mathrm{M-CSF}$ and $2 \mathrm{ng} / \mathrm{ml}$ RANKL on glass for 4 and 7 days. In the merged image of TRAP 5a and total TRAP, areas shown in white have TRAP 5a and TRAP $5 \mathrm{~b}$ and areas staining exclusively magenta have predominantly TRAP

CD14+ PBMCs differentiated with M-CSF-and RANKL were analyzed by ICC staining with TRAP 5a-specific $\mathrm{mAb} 46$ and total $(5 \mathrm{a}+5 \mathrm{~b})$ polyclonal TRAP-antibody on glass (Fig. 5a) or on bone (Fig. 5b) using confocal 5b. b Staining for TRAP 5a (green) total TRAP (magenta) and actin (gray) using ICC in OC differentiated from CD14+ PBMCs-stimulated M-CSF and RANKL for 4 and 8 days on bone-coated coverslips. In the merged image, areas shown in white have TRAP 5a and TRAP $5 \mathrm{~b}$ and areas staining exclusively magenta have predominantly TRAP $5 b$

microscopy. M-CSF + RANKL-treated PBMCs cultured on glass demonstrated TRAP 5a signal (green) at 4 days of culture in a vast majority of both mono- and multinuclear cells (Fig. 5a). In addition, total TRAP (magenta) 
was present in most cells, although a small population of mononuclear as well as a few multinuclear cells displayed very high total TRAP staining (Fig. 5a). The levels of total TRAP staining varied considerably between cells, and in the cells with high total TRAP signal, the isoforms appeared to be predominantly co-localized (white areas) in a perinuclear area of the cells. At day 7, both mononuclear and multinucleated cells stained positive for TRAP 5a, but the multinucleated cells displayed only weak intracellular total TRAP staining, whereas high total TRAP signals were detected in a subset of mononuclear cells. Furthermore, the co-localization of TRAP 5a and total TRAP in multinucleated cells was lower on day 7 compared to day 4 , suggesting that the antibodies stain different compartments, and the compartments stained exclusively magenta in the merged figure could represent stored TRAP 5b.

On bone-coated coverslips [32], TRAP 5a was more widely spread throughout the cell compared to total TRAP and abundant in both mono- and multinuclear cells stimulated with M-CSF + RANKL (Fig. 5b). At day 4, most mononuclear cells were positive for TRAP 5a, whereas a subset of these mononuclear cells were also positive for total TRAP. The localization of the two stains showed very little overlap on day 4 and several compartments stained exclusively magenta in the merged image, suggesting the presence of intracellular compartments with TRAP 5b (Fig. 5b). The most striking difference regarding TRAP 5a was observed in multinucleated cells exhibiting actin structures resembling sealing zones at day 8 . These cells exhibited perinuclear structures that were strongly stained for TRAP 5a and this staining overlapped to a high degree with staining for total TRAP (Fig. 5b), indicating the presence of TRAP 5a also in resorbing multinuclear cells. In addition to the strong perinuclear staining, a few vesicles in the same cells were positive for only total TRAP. Similar vesicles positive for only total TRAP, indicating the presence of TRAP 5b, were found also in other multinuclear and mononuclear cells (Fig. 5b).

\section{Intracellular Production and Secretion of TRAP $5 a$ and $5 b$ from CD14+ PBMCs Cultured on Plastic and Bone in Response to RANKL}

To assess kinetics of generation and secretion of TRAP isoforms from CD14+ derived OCs, intracellular (cell lysate) and extracellular (culture media) TRAP 5a and 5b concentrations were measured (Fig. 6). In cultures on plastic, secretion (medium) of TRAP 5b and TRAP 5 a from cultures differentiated with RANKL + M-CSF were significantly higher from day 4 onwards compared to day 3 of culture (Fig. 6a). Concentrations of TRAP 5b showed a constant increase over the culture period and it was the predominant secreted isoform throughout the culture. Cells stimulated with M-CSF alone secreted low basal amounts of both isoforms without a significant increase over the culture period.

On plastic, intracellular (lysate) TRAP 5b protein concentrations increased rapidly between days 3 and 4 in M-CSF + RANKL-stimulated cells and were significantly higher from day 4 of culture. The increase of TRAP 5a concentrations occurred later and they were significantly higher from day 6 of culture. In the cell culture lysates stimulated with M-CSF alone, concentrations of both TRAP isoforms were low, consistent with the TRAP activity staining (Supplementary figure 3). During OC differentiation, TRAP 5b concentrations increased over 20 -fold, both in lysate and medium, compared to day 3 where no multinuclear cells were present.

In cultures grown on bone chips, a significant increase in the secretion of TRAP 5b was apparent from day 6 of culture in M-CSF + RANKL-stimulated cells compared to day 4 (Fig. 6c).

Thus, secretion occurred later on bone than in cultures grown on plastic, and secreted concentrations were much higher than on plastic, both matching observations from the TRAP activity staining (Supplementary figure 3). Also, secretion of TRAP 5a increased significantly on day 8 of culture in M-CSF + RANKL-stimulated cells (Fig. 6c), but remained lower than secreted TRAP 5b. Overall, the pattern of TRAP isoform secretion seems to be similar on bone and plastic. In lysates, there was a corresponding increase in both isoforms (high for TRAP $5 b$ and moderate for 5a), from day 8 coinciding with the appearance of OCs (cf. Supplementary figure 3B). Put together, cultures grown on bone produced more TRAP isoforms prompting us to investigate its connection with bone resorption, especially as cells with sealing zones display high levels of intracellular TRAP isoforms (Fig. 5b).

The bone resorption marker CTX-I was detectable in medium from day 6 and increased progressively to day 12 (Fig. 6e). Intracellular TRAP 5b was detectable prior to production of CTX-I, indicating that TRAP production emerges before onset of resorption and intracellular processing of TRAP 5a to TRAP 5b (Fig. 6c, e). The ratio of CTX-I/TRAP $5 \mathrm{~b}$ in the medium showed a strong increase on day 8 of the culture period suggesting an active role for TRAP $5 \mathrm{~b}$ in facilitating bone resorption activity (Fig. 6f). The relative ratios of TRAP isoforms $5 \mathrm{~b} / 5 \mathrm{a}$ and CTX-I/5a increased up to day 8 and decreased thereafter. This decrease was due to a continued secretion of TRAP 5 a at later culture time points and coincided with gradual saturation of CTX-I-output.

Concentrations of TRAP $5 \mathrm{a}$ and $5 \mathrm{~b}$ protein from in vitro OC differentiation on bone correlated moderately high, and positively to each other (Fig. 6g). Also, both TRAP 5a and TRAP 5b protein levels correlated positively with CTX-I (Figs. 4i, 6h) similar to the observation in human serum 

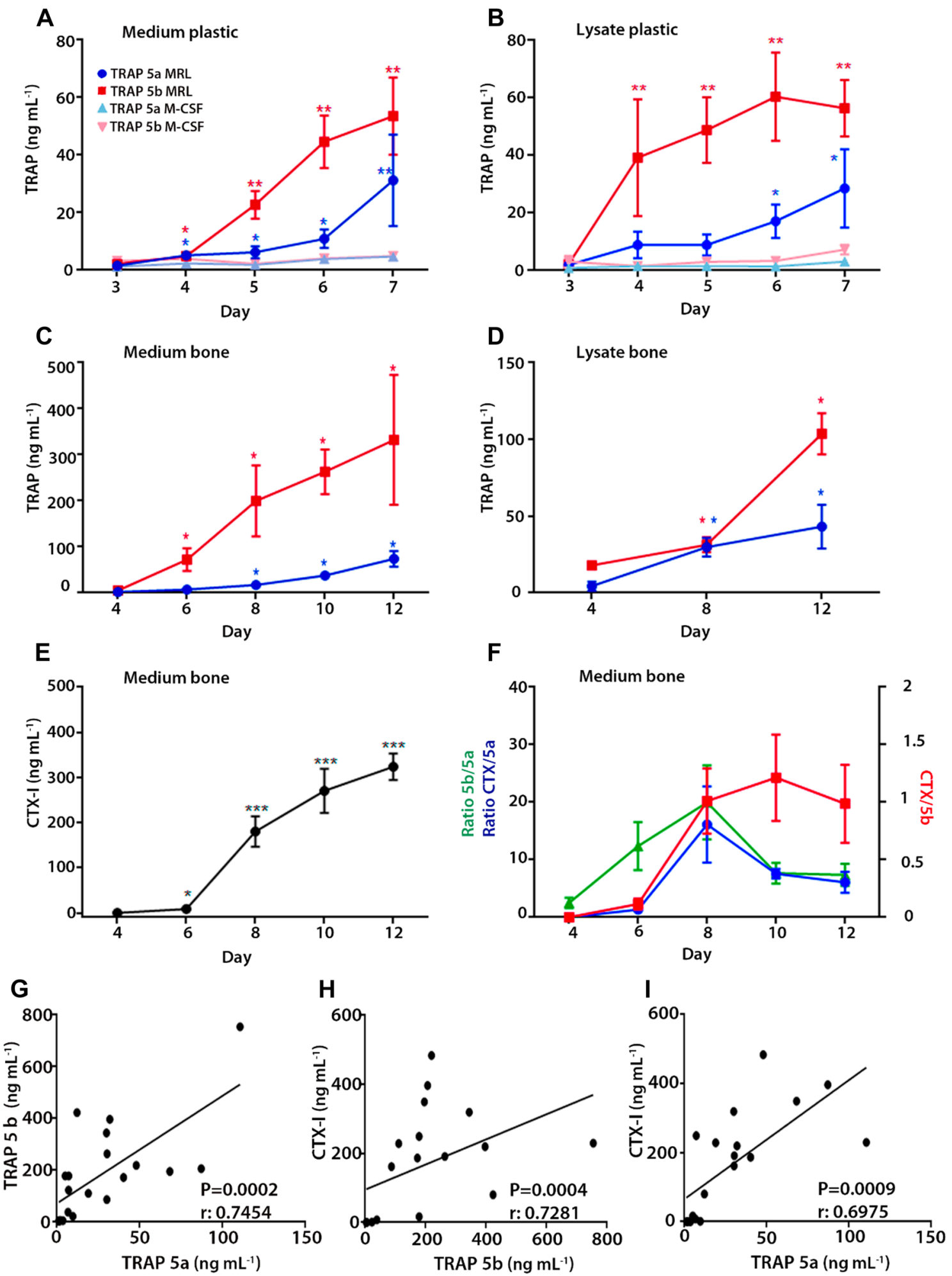

(cf. Fig. 3), suggesting that a considerable fraction of serum TRAP 5a could derive from differentiating OCs.

\section{Discussion}

The assay design used for the double-TRAP $5 \mathrm{a} / 5 \mathrm{~b}$ sandwich ELISA was to capture TRAP 5a with a high-affinity TRAP 5a-specific antibody (mAb 46) [28] and then transfer the 
4Fig. 6 TRAP 5a and 5b production, secretion, and correlation during RANKL-dependent OC differentiation from CD14+ cells on bone and plastic. All cells in the in vitro cultures were treated with $30 \mathrm{ng} /$ $\mathrm{ml}$ M-CSF or $30 \mathrm{ng} / \mathrm{ml}$ M-CSF and $2 \mathrm{ng} / \mathrm{ml}$ RANKL a Measurement of secreted TRAP $5 \mathrm{a}$ and $5 \mathrm{~b}$ protein in media from OC differentiated from CD14+ PBMCs on plastic $(n=6)$. b Measurement of intracellular TRAP $5 \mathrm{a}$ and $5 \mathrm{~b}$ protein in lysate from $\mathrm{OC}$ on plastic from OC differentiating CD14+ PBMCs $(n=6)$. c Measurement of secreted TRAP $5 \mathrm{a}$ and $5 \mathrm{~b}$ protein in media from OC differentiated from CD14+ PBMCs stimulated on bovine bone discs $(n=4)$. d Measurement of intracellular TRAP $5 \mathrm{a}$ and $5 \mathrm{~b}$ protein lysate from OC differentiating CD14+ PBMCs stimulated on bovine bone discs $(n=4)$. E. Detected increased of CTX-I in medium from day 4 to 12 . Concentrations on day 4-12 were compared to day 3 or 4 using Mann-Whitney $U$ test. Values are given as mean \pm SEM. $* p<0.05$; $* * p<0.01$; $* * * p<0.001$. $\mathbf{f}$ Ratio of CTX-I compared to TRAP 5a and TRAP 5b. g Positive correlation between TRAP5a and TRAP 5b $(n=19)$ from CD14+ CD14+ PBMCs stimulated on bovine bone discs for a period of 12 days. $\mathbf{h}$ Positive correlation between TRAP 5b and CTX-I $(n=19)$ from CD14+ PBMCs stimulated on bovine bone discs for a period of 12 days. i Positive correlation between TRAP 5a and CTX-I $(n=19)$ from CD14+ PBMCs stimulated on bovine bone discs for a period of 12 days. Correlation analysis was done using Spearman's correlation. ${ }^{*} p<0.05 ; * * p<0.01 ; * * * p<0.001$

supernatant, containing TRAP $5 \mathrm{~b}$, to a well coated with a capture antibody recognizing both isoforms with equal affinity (mAb 25.44). Both isoforms were then detected with a biotin-labeled pan TRAP 5a/5b antibody (mAb12.56). This design allowed quantification of both isoforms from a single sample and circumvented the requirement for producing TRAP 5b-specific antibodies. However, TRAP 5a was partly carried over to mAb 25.44 when measuring TRAP 5b on mAb 25.44 after TRAP 5a capture. Sample-dependent carry-over is a known problem and there are established protocols to detect and compensate for it [33]. The extent of TRAP 5a carry-over was inferred from transferred TRAP 5 a standard curve and subtracted from the measured TRAP 5 b signal in the double-TRAP $5 \mathrm{a} / 5 \mathrm{~b}$ sandwich, thus enabling measurement of TRAP $5 b$ protein concentrations. No statistical difference was seen between expected concentration and corrected concentrations of TRAP 5b, although a slight under recovery is possible, e.g. due to non-specific binding. Validation of the TRAP $5 \mathrm{a} / 5 \mathrm{~b}$ double ELISA was made according to Armbruster [34] when/if the ELISA will be subject for commercialization/diagnostic use in laboratories, validation in accordance with the FDA guidelines for method validation, "Bioanalytical Method Validation Guidance for Industry" will be applied.

TRAP 5a and 5b were measured in serum where TRAP 5a levels in healthy men were in the same range as for the TRAP 5a ELISA [28], but slightly lower than reported for serum TRAP 5a using other assays [35, 36]. Comparing serum TRAP $5 \mathrm{~b}$ protein levels in healthy men to previously published TRAP 5b assays [12, 37] was not feasible since these IIAAs are based on antibody capture followed by TRAP activity measurement. However, human serum TRAP
$5 \mathrm{a}$ and $5 \mathrm{~b}$ protein have been separated by chromatography followed by TRAP measurement showing that TRAP 5a constitutes $\sim 87 \%$ while TRAP $5 \mathrm{~b}$ is $\sim 13 \%$ of total TRAP protein in human serum [38]. This is comparable to $75 \%$ vs $25 \%$ for TRAP $5 \mathrm{a}$ and $5 \mathrm{~b}$ protein in human serum measured with the double-TRAP 5a/5b sandwich ELISA.

Serum TRAP 5a and $5 \mathrm{~b}$ protein levels were found to be positively, moderately correlated in healthy men, while TRAP 5a and 5b activities were not correlated [21]. The specific activity of TRAP $5 \mathrm{~b}$ at $\mathrm{pH} 5.8-6.0$ is approximately 10 times higher than for TRAP 5a [39]; however, serum concentration of TRAP 5a is 3-5 times higher than TRAP 5b. In an IIAA, where an antibody captures both isoforms and the read-out is based on TRAP enzyme activity, the contributions of the TRAP $5 \mathrm{a}$ and TRAP $5 \mathrm{~b}$ isoforms are in the range of 35-50\% and 50-65\%, respectively, when considering the relative abundance and phosphatase activity as a compound read-out [3]. However, even this estimation is sensitive to the redox state of TRAP in the sample and to any interference from TRAP-binding proteins, e.g. a2M [40]. Therefore, it is important to measure TRAP $5 \mathrm{a}$ and $5 \mathrm{~b}$ protein concentrations independent from their enzyme activity.

Serum TRAP 5b, marker of OC number, was also moderately and positively correlated to the resorption marker CTX-I, in line with previous studies showing that TRAP 5b measured using IIAA is positively correlated to CTX-I in women [37, 41]. Interestingly, our results showed that TRAP 5a also correlated moderately positive to CTX-I in healthy men, indicating a coupling between TRAP 5a protein levels and bone resorption activity in healthy men.

The moderate correlation of TRAP 5a and TRAP 5b with CTX-I led us to investigate the production and secretion of TRAP isoforms in RANKL-differentiated CD14+ OCs on plastic and bone in vitro, in order to assess how the presence and secretion of TRAP isoforms are related to the resorption and differentiation of OCs. In relation to TRAP 5a and $5 \mathrm{~b}$ proteins, some TRAP activity (TRAP staining) was observed in M-CSF-stimulated cells, consistent with the reported differentiation stage of CD14+-circulating monocytes [42], meaning that they express minute levels of TRAP. In addition, with ICC, TRAP 5a protein was found in the majority of RANKL-stimulated mononuclear and osteoclast-like cells and OCs, and it exhibited a diffuse cytoplasmic localization. Conversely, there was more variation in TRAP 5b (i.e. the difference between ICC signal for TRAP 5a and total TRAP), as a few mononuclear and multinucleated cells stained very bright, while most cells showed a low signal. This, in part, further validated that the antibodies used in the ELISA indeed bind different intracellular targets. In resorbing OCs, TRAP 5a and 5b co-localized in a perinuclear compartment and some TRAP 5b was confined to vesicular compartments. The presence of TRAP 5b was 
not exclusively observed in multinuclear cells, suggesting that the processing of TRAP 5a to $5 \mathrm{~b}$ starts already in some mononuclear pre-OCs.

With the novel ELISA, intracellular TRAP 5b protein levels were shown to increase during RANKL-stimulated OC differentiation rapidly and significantly, simultaneously with the formation of TRAP + multinucleated cells. Concomitantly, significant amounts of TRAP $5 b$ were secreted into the medium, consistent with previous reports [43]. Both intracellular and extracellular TRAP 5b concentrations were constantly higher than TRAP 5a concentrations, indicating efficient proteolytic processing of TRAP 5a in differentiating OCs. In addition, the steady increase in extracellular TRAP $5 \mathrm{~b}$ concentration occurred slower than the increase in intracellular concentration. Together with the steady secretion measured in the ELISA, this observation could suggest that intracellular TRAP $5 \mathrm{~b}$ generation by proteolytic processing may precede resorption and secretion.

Intracellular TRAP 5a protein levels increased upon RANKL stimulation although not to the same extent as TRAP 5b. In line with this, TRAP 5a secretion was also increased after RANKL stimulation on both plastic and bone. Measured concentrations of intracellular and secreted TRAP $5 \mathrm{a}$ and $5 \mathrm{~b}$ are in line with a previous study [44]. Interestingly, secretion of TRAP 5a increased progressively while TRAP 5 b gradually decreased, possibly indicating that increased 5a secretion during later stages of the resorption cycle could exert distinct roles from $5 \mathrm{~b}$. In diagnostic settings, this observation could facilitate identification of cases where the balance of bone remodeling switches towards resorption.

However, much higher amounts of TRAP $5 \mathrm{a}$ and $5 \mathrm{~b}$ were secreted from CD14+-derived OCs cultured on bone than on plastic, indicating that stimulus to begin resorption leads also to augmented secretion of TRAP 5b. This suggests that TRAP 5a is secreted in high amounts upon resorption which could be consistent with the observed stronger TRAPactivity staining on bone slices and TRAP ICC staining in resorbing OCs. Therefore, TRAP isoforms reflect not only OC numbers but also activity.

These observations are consistent with the model of OC differentiation where RANKL stimulus leads to NF-kB activation that activates transcription and dephosphorylation of NFATc1 that in turn induces transcription of OC-associated genes including Acp5 $[8,45]$. This signaling accounts for the initial TRAP production. The higher TRAP concentrations on bone compared to plastic are likely due to osteoclastassociated receptor (OSCAR)-mediated recognition of mineralized collagen combined with RGD recognition by integrin $\alpha_{\mathrm{V}} \beta_{3}$ [46]. The rise and fall of the TRAP 5a/5b ratio, not observed in individual measures of $5 \mathrm{a}, 5 \mathrm{~b}$ or CTX-I suggest that it may be a more sensitive biomarker for OC activity and fluctuations in bone resorption.
Serum TRAP 5a and 5b correlated moderately and positively not only to each other but also resorption marker, CTX-I. As there is a chance that moderate correlation between biological variables does not show a true biological relationship, we continued to investigate the relationship between TRAP 5a, 5b and CTX-I also in an in vitro OC system. Similarly, in the in vitro model, TRAP $5 \mathrm{a}$ and $5 \mathrm{~b}$ concentrations correlated moderately-high and positively to each other, and to CTX-I throughout the culture. However, there are changes in the concentration in respect to each other over the culture period, and the pattern of secretion for the TRAP isoforms did not fully coincide with CTX-I production. The positive correlation in both serum and the in vitro OC system indicates that there is a interdependence between TRAP 5a, 5b and CTX-I. Future studies should therefore aim to investigate this relationship in larger cohorts to establish the clinical relevance of such a correlation. From a diagnostic perspective, these findings suggest that in healthy conditions, at least part of serum TRAP 5a is linked to OC-dependent secretion of TRAP 5a. Furthermore, as shown by the difference between in vitro cultures on plastic and bone, TRAP 5b reflects not only number of OCs but also their activity. In clinical use, our new TRAP $5 \mathrm{a} / 5 \mathrm{~b}$ ELISA could be useful in the characterization of bone pathologies such as pycnodysostosis [47] where osteoclast numbers increase, while resorption activity remains low and presumably the distribution of TRAP isoforms will be altered.

In conclusion, a new TRAP sandwich ELISA measuring both TRAP $5 \mathrm{a}$ and $5 \mathrm{~b}$ protein levels independently from the same sample has been developed and validated. The measurement of serum TRAP $5 \mathrm{a}$ and $5 \mathrm{~b}$ protein levels shows differences compared to IIAAs, strengthening the importance of measuring protein levels directly. Applying the new double-TRAP 5a/5b sandwich ELISA revealed that TRAP 5 a correlates moderately to TRAP $5 b$ in healthy males, and to the resorption marker, CTX-I. The new ELISA could also verify that in vitro-cultured CD14+-derived OC secreted both TRAP $5 \mathrm{a}$ and $5 \mathrm{~b}$ proteins, and that this secretion was correlated moderately high to each other as well as to CTXI. This indicates that not only TRAP $5 \mathrm{~b}$ isoform in human blood is derived from osteoclasts, but that also a considerable proportion of the TRAP isoform 5a originates from osteoclasts and may reflect a hitherto undisclosed regulatory mechanism during bone resorption and bone remodeling.

Acknowledgements Open access funding provided by Karolinska Institute. This work was supported by Grants from Marie Curie Initial Training Network (Euroclast, FP7-People-2013-ITN:\#607447), ERC FP7 Health-2007-A (SP), Loo and Hans Osterman foundation (TN), Maud Kuistila Memorial foundation (TN), Jane and Aatos Erkko foundation (TN), and the Swedish Research Council [\#K201599X-10363-23-4 (GA)] and [\#2017-01083 (TN)], and the support of the Marie Curie Alumni Association (LM). For technical assistance, 
we would like to thank Dane Blasser and Anni-Frid Henriksson. We would like to thank Anh Nhi Tran for her helpful comments and proof reading this article.

\section{Compliance with Ethical Standards}

Conflict of interest For this study, Prof. Göran Andersson received research support from the Swedish Research Council, Dr. Staffan Paulie received research support from the European Research Council, and Dr. Tuomas Näreoja received research support from Jane and Aatos Erkko Foundation. Dr. Näreoja reports non-financial support from Mabtech Inc. during the conduct of the study. Dr. Staffan Pauli is a former CEO, shareholder, and current member of the board of directors of Mabtech Inc. The antibodies used in the study are considered for commercialization by Mabtech Inc. Laia Mira-Pascual, Christina Patlaka, Suchita Desaia, and Pernilla Lång declare that they have no conflict of interest.

Human and Animal Rights and Informed Consent Human peripheral blood monocytes (hPBMC) were isolated from buffy coats of donated blood of healthy men at Karolinska University Hospital Laboratory, Huddinge, Sweden. The surplus blood products were coded for research use. The study was performed in accordance of guidelines from Swedish Research Council and Karolinska Institutet. All donors involved in the study gave written informed consent in accordance with the Helsinki Declaration.

Open Access This article is distributed under the terms of the Creative Commons Attribution 4.0 International License (http://creativeco mmons.org/licenses/by/4.0/), which permits unrestricted use, distribution, and reproduction in any medium, provided you give appropriate credit to the original author(s) and the source, provide a link to the Creative Commons license, and indicate if changes were made.

\section{References}

1. Bune AJ, Hayman AR, Evans MJ, Cox TM (2001) Mice lacking tartrate-resistant acid phosphatase (Acp 5) have disordered macrophage inflammatory responses and reduced clearance of the pathogen, Staphylococcus aureus. Immunology 102:103-113. https://doi.org/10.1046/j.1365-2567.2001.01145.x

2. Lv Y, Wang G, Xu W et al (2015) Tartrate-resistant acid phosphatase $5 \mathrm{~b}$ is a marker of osteoclast number and volume in RAW 264.7 cells treated with receptor-activated nuclear $\mathrm{\kappa B}$ ligand. Exp Ther Med 9:143-146. https://doi.org/10.3892/etm.2014.2071

3. Ljusberg J, Ek-Rylander B, Andersson G (1999) Tartrate-resistant purple acid phosphatase is synthesized as a latent proenzyme and activated by cysteine proteinases. Biochem J 69:63-69. https:// doi.org/10.1042/0264-6021:3430063

4. Lång $\mathrm{P}$, van Harmelen V, Ryden $\mathrm{M}$ et al (2008) Monomeric tartrate resistant acid phosphatase induces insulin sensitive obesity. PLoS ONE 3:e1713

5. Ek-Rylander B, Flores M, Wendel M et al (1994) Dephosphorylation of osteopontin and bone sialoprotein by osteoclastic tartrateresistant acid phosphatase. Modulation of osteoclast adhesion in vitro. J Biol Chem 269:14853-14856

6. Briggs TA, Rice GI, Adib N et al (2016) Spondyloenchondrodysplasia due to mutations in ACP5: a comprehensive survey. J Clin Immunol 36:220-234. https://doi.org/10.1007/s10875-016-0252-y

7. Kim J, Kim N (2016) Signaling pathways in osteoclast differentiation. Chonnam Med J 52:12-17. https://doi.org/10.4068/ cmj.2016.52.1.12
8. Takayanagi H, Kim S, Koga T et al (2002) Induction and activation of the transcription factor NFATc1 (NFAT2) integrate RANKL signaling in terminal differentiation of osteoclasts. Dev Cell 3:889-901. https://doi.org/10.1016/S1534-5807(02)00369-6

9. Väärniemi J, Halleen JM, Kaarlonen K et al (2004) Intracellular machinery for matrix degradation in bone resorbing osteoclasts. J Bone Min Res 19:1932-1940

10. Ljusberg J, Wang Y, Lång P et al (2005) Proteolytic excision of a repressive loop domain in tartrate-resistant acid phosphatase by cathepsin K in osteoclasts. J Biol Chem 280:28370-28381. https ://doi.org/10.1074/jbc.M502469200

11. Lau I-HW, Onishi T, Wergedal JE et al (1987) Characterization and assay of tartrate-resistant acid phosphatase activity in serum: potential use to assess bone resorption materials and methods. Clin Chem 334:458-462

12. Alatalo SL, Halleen JM, Hentunen TA, Mo J (2000) Rapid screening method for osteoclast differentiation in vitro that measures tartrate-resistant acid phosphatase $5 \mathrm{~b}$ activity secreted into the culture medium. Clin Chem 1754:1751-1754

13. Scarnecchia L, Minisola S, Pacitti MT et al (1991) Clinical usefulness of serum tartrate-resistant acid phosphatase activity determination to evaluate bone turnover. Scand J Clin Lab Invest 51:517-524. https://doi.org/10.3109/00365519109104560

14. Kraenzlin ME, Lau K-HW, Liang L et al (1990) Development of an immunoassay for human serum osteoclastic tartrate-resistant acid phosphatase. J Clin Endocrin Metab 71:442-451

15. Cheung CK, Panesar NS, Haines C et al (1995) Immunoassay of a tartrate-resistant acid phosphatase in serum. Clin Chem 41:679-686

16. Chamberlain P, Compston J, Cox TM et al (1995) Generation and characterization of monoclonal antibodies to human type- 5 tartrate-resistant acid phosphatase: development of a specific immunoassay of the isoenzyme in serum. Clin Chem 41:1495-1499

17. Halleen JM, Hentunen TA, Karp M et al (1998) Characterization of serum tartrate-resistant acid phosphatase and development of a direct two-site immunoassay. J Bone Min Res 13:683-687. https ://doi.org/10.1359/jbmr.1998.13.4.683

18. Alatalo SL, Ivaska KK, Waguespack SG et al (2004) Osteoclast-derived serum tartrate-resistant acid phosphatase $5 \mathrm{~b}$ in Albers-Schönberg disease (type II autosomal dominant osteopetrosis). Clin Chem 50:883-890. https://doi.org/10.1373/clinc hem.2003.029355

19. Rissanen JP, Suominen MI, Peng Z, Halleen JM (2008) Secreted tartrate-resistant acid phosphatase $5 \mathrm{~b}$ is a marker of osteoclast number in human osteoclast cultures and the rat ovariectomy model. Calcif Tissue Int 82:108-115. https://doi.org/10.1007/ s00223-007-9091-4

20. Fagerlund KM, Janckila AJ, Ylipahkala H et al (2008) Clinical performance of six different serum tartrate-resistant acid phosphatase assays for monitoring alendronate treatment. Clin Lab 54:347-354

21. Halleen JM, Ylipahkala H, Alatalo SL et al (2002) Serum tartrate-resistant acid phosphatase $5 \mathrm{~b}$, but not $5 \mathrm{a}$, correlates with other markers of bone turnover and bone mineral density. Calcif Tissue Int 71:20-25. https://doi.org/10.1007/s0022 3-001-2122-7

22. Cheng T, Wang M, Chen Z et al (2014) Tartrate-resistant acid phosphatase $5 \mathrm{~b}$ is a potential biomarker for rheumatoid arthritis: a pilot study in han chinese. Chin Med J (Engl) 127:2894-2899. https://doi.org/10.3760/cma.j.issn.0366-6999.20140670

23. Luukkonen J, Pascual LM, Patlaka C et al (2017) Increased amount of phosphorylated proinflammatory osteopontin in rheumatoid arthritis synovia is associated to decreased tartrateresistant acid phosphatase 5B/5A ratio. PLoS ONE. https://doi. org/10.1371/journal.pone.0182904 
24. Brehme CS, Roman S, Shaffer J, Wolfert R (1999) Tartrateresistant acid phosphatase forms complexes with alpha2-macroglobulin in serum. J Bone Min Res 14:311-318

25. Terpos E, De La Fuente J, Szydlo R et al (2003) Tartrateresistant acid phosphatase isoform $5 \mathrm{~b}$ : a novel serum marker for monitoring bone disease in multiple myeloma. Int J Cancer 106:455-457. https://doi.org/10.1002/ijc.11247

26. Janckila AJ, Neustadt DH, Yam LT (2008) Significance of serum TRACP in rheumatoid arthritis. J Bone Miner Res 23:1287-1295. https://doi.org/10.1359/JBMR.080329

27. Janckila AJ, Slone SP, Lear SC et al (2007) Tartrate-resistant acid phosphatase as an immunohistochemical marker for inflammatory macrophages. Am J Clin Pathol 127:556-566. https:// doi.org/10.1309/DGEA9BE2VE5VCFYH

28. Patlaka C, Mira Pascual L, Paulie S et al (2017) The adipokine tartrate-resistant acid phosphatase $5 \mathrm{a}$ in serum correlates to adipose tissue expansion in obesity. Biomarkers 22:764-774. https ://doi.org/10.1080/1354750X.2017.1334155

29. Armbruster DA, Pry T (2008) Limit of blank, limit of detection and limit of quantitation. Clin bBiochem Rev 29:49-52

30. Hinkle D, Wiersma W, Jurs S (2003) Applied statistics for the behavioral sciences, 5th edn. Houghton Mifflin, Boston

31. Janckila AJ, Yam LT (2009) Biology and clinical significance of tartrate-resistant acid phosphatases: new perspectives on an old enzyme. Calcif Tissue Int 85:465-483. https://doi.org/10.1007/ s00223-009-9309-8

32. Deguchi T, Alanne MH, Fazeli E et al (2016) In vitro model of bone to facilitate measurement of adhesion forces and superresolution imaging of osteoclasts. Sci Rep 6:22585. https://doi. org/10.1038/srep22585

33. Kavsak PA, Zeidler J (2016) Carryover: more than just a major hangover for the clinical laboratory. Clin Biochem 49:735-736. https://doi.org/10.1016/J.CLINBIOCHEM.2016.05.020

34. Armbruster DA, Pry T (2008) Limit of blank, limit of detection and limit of quantitation. Clin Biochem Rev 29(Suppl 1):S49-S52

35. Shih K-C, Janckila AJ, Kwok C-F et al (2010) Effects of exercise on insulin sensitivity, inflammatory cytokines, and serum tartrate-resistant acid phosphatase $5 \mathrm{a}$ in obese Chinese male adolescents. Metabolism 59:144-151. https://doi.org/10.1016/j.metab ol.2009.06.035

36. Shih K-C, Janckila AJ, Lee W-J et al (2015) Effects of bariatric weight loss surgery on glucose metabolism, inflammatory cytokines, and serum tartrate-resistant acid phosphatase $5 \mathrm{a}$ in obese Chinese adults. Clin Chim Acta 30:197-202. https://doi. org/10.1016/j.cca.2015.11.004
37. Halleen JM, Alatalo SL, Suominen H et al (2000) Tartrate-resistant acid phosphatase $5 \mathrm{~b}$ : a novel serum marker of bone resorption. J Bone Miner Res 15:1337-1345

38. Janckila AJ, Takahashi K, Sun SZ, Yam LT (2001) Tartrate-resistant acid phosphatase isoform $5 \mathrm{~b}$ as serum marker for osteoclastic activity. Clin Chem 47:74-80

39. Ek-Rylander B, Barkhem T, Ljusberg J et al (1997) Comparative studies of rat recombinant purple acid phosphatase and bone tartrate-resistant acid phosphatase. Biochem J 321(2):305-311

40. Ylipahkala H, Halleen JM, Kaija H et al (2003) Tartrate-resistant acid phosphatase 5B circulates in human serum in complex with alpha2-macroglobulin and calcium. Biochem Biophys Res Commun 308:320-324

41. Hannon RA, Clowes JA, Eagleton AC et al (2004) Clinical performance of immunoreactive tartrate-resistant acid phosphatase isoform $5 \mathrm{~b}$ as a marker of bone resorption. Bone 34:187-194. https://doi.org/10.1016/j.bone.2003.04.002

42. Aldridge SE, Lennard TWJ, Williams JR, Birch MA (2005) Vascular endothelial growth factor acts as an osteolytic factor in breast cancer metastases to bone. Br J Cancer 92:1531-1537. https ://doi.org/10.1038/sj.bjc.6602417

43. Wang Y, Andersson G (2007) Expression and proteolytic processing of mammalian purple acid phosphatase in CHO-K1 cells. Arch Biochem Biophys 461:85-94. https://doi.org/10.1016/j. abb.2007.01.025

44. Kim JH, Kim N (2014) Regulation of NFATc1 in osteoclast differentiation. J Bone Metab 21:233-241. https://doi.org/10.11005 /jbm.2014.21.4.233

45. Park JH, Lee NK, Lee SY (2017) Current understanding of RANK signaling in osteoclast differentiation and maturation. Mol Cells 40:706-713. https://doi.org/10.14348/molcells.2017.0225

46. Janckila AJ, Parthasarathy RN, Parthasarathy LK et al (2005) Properties and expression of human tartrate-resistant acid phosphatase isoform 5a by monocyte-derived cells. J Leukoc Biol 77:209-218. https://doi.org/10.1189/jlb.0504287

47. Brömme D, Panwar P, Turan S (2016) Cathepsin K osteoporosis trials, pycnodysostosis and mouse deficiency models: commonalities and differences. Expert Opin Drug Discov 11:457-472. https ://doi.org/10.1517/17460441.2016.1160884

Publisher's Note Springer Nature remains neutral with regard to jurisdictional claims in published maps and institutional affiliations. 